\title{
Tissue Doppler echocardiography and biventricular pacing in heart failure: Patient selection, procedural guidance, follow-up, quantification of success
}

\author{
Fabian Knebel ${ }^{1}$, Rona Katharina Reibis ${ }^{2}$, Hans-Jürgen Bondke ${ }^{1}$, \\ Joachim Witte ${ }^{1}$, Torsten Walde ${ }^{1}$, Stephan Eddicks ${ }^{1}$, Gert Baumann ${ }^{1}$ and \\ Adrian Constantin Borges*1
}

Address: ${ }^{1}$ Charité Campus Mitte - University Medicine Berlin, Medical Clinic for Cardiology, Angiology, Pneumology, 10098 Berlin, Germany and ${ }^{2}$ Klinik am See, Department of Cardiology, Rehabilitation Center of Cardiovascular Diseases, Seebad 84, 15562 Rüdersdorf (Berlin), Germany

Email: Fabian Knebel - fabian.knebel@charite.de; Rona Katharina Reibis - rona.reibis@klinikamsee.com; Hans-

Jürgen Bondke - hansjuergen.bondke@charite.de; Joachim Witte - joachim.witte@charite.de; Torsten Walde - t-walde@gmx.de;

Stephan Eddicks - stephan.eddicks@charite.de; Gert Baumann - gert.baumann@charite.de;

Adrian Constantin Borges* - adrian.borges@charite.de

* Corresponding author

Published: 15 September 2004

Cardiovascular Ultrasound 2004, 2:17 doi:10.1186/1476-7/20-2-17
Received: 22 July 2004

Accepted: 15 September 2004

This article is available from: http://www.cardiovascularultrasound.com/content/2/I/17

(c) 2004 Knebel et al; licensee BioMed Central Ltd.

This is an open-access article distributed under the terms of the Creative Commons Attribution License (http://creativecommons.org/licenses/by/2.0), which permits unrestricted use, distribution, and reproduction in any medium, provided the original work is properly cited.

\begin{abstract}
Asynchronous myocardial contraction in heart failure is associated with poor prognosis. Resynchronization can be achieved by biventricular pacing (BVP), which leads to clinical improvement and reverse remodeling. However, there is a substantial subset of patients with wide QRS complexes in the electrocardiogram that does not improve despite BVP. QRS width does not predict benefit of BVP and only correlates weakly with echocardiographically determined myocardial asynchrony. Determination of asynchrony by Tissue Doppler echocardiography seems to be the best predictor for improvement after BVP, although no consensus on the optimal method to assess asynchrony has been achieved yet. Our own preliminary results show the usefulness of Tissue Doppler Imaging and Tissue Synchronization Imaging to document acute and sustained improvement after BVP. To date, all studies evaluating Tissue Doppler in BVP were performed retrospectively and no prospective studies with patient selection for BVP according to echocardiographic criteria of asynchrony were published yet. We believe that these new echocardiographic tools will help to prospectively select patients for BVP, help to guide implantation and to optimize device programming.
\end{abstract}

\section{Background}

Heart failure is among the most common chronic diseases in modern civilizations. The dilatation of the left ventricle frequently induces intracardiac conduction delays result- ing in asynchronous left ventricular motion. This manifests as left bundle branch block in the surface ECG. Both QRS width and intraventricular asynchrony are predictors 
of hospitalization and severe cardiac events in patients with heart failure [1-3].

The mechanisms of myocardial asynchrony include a delayed left ventricular regional contraction and relaxation. The right ventricle contracts during left ventricular end-diastole, leading to a "bulging" of the septum into the left ventricle. The intra(left)ventricular delay of the systolic velocity induces the "delayed longitudinal contraction (DLC)". Furthermore, the delay of the contraction of the papillary muscles aggravates mitral regurgitation. This, in summary, leads to an increased oxygen demand of the myocardium [4].

Resynchronization of the intraventricular conduction can be achieved by introducing an additional lead through the coronary venous sinus to stimulate the left ventricle (biventricular pacing, BVP). The combination of BVP and a cardioverter-defibrillator (ICD) combines the clinical improvement by BVP and reduction in mortality [5]. Recent studies have shown an acute and sustained hemodynamic improvement, reversal of LV-remodeling, an increased quality of life, a reduction of symptoms of heart failure, and improvement of exercise tolerance after biventricular pacing. Markers of reverse remodeling were reduction of left ventricular volumes, increase in LVEF without an increase in oxygen consumption, reduction of mitral regurgitation [6-10]. However, a significant reduction of mortality after BVP alone could not be demonstrated.

In the current guidelines, LBBB in the surface ECG and a reduced LVEF are the main indications for BVP [11]. However, about one third of patients in the large multicenter BVP studies did not improve - despite BVP $[6,7,12]$. There is increasing evidence, that there is only a weak correlation of electrical (QRS width) and mechanical asynchrony and the benefit of BVP. It seems that not all heart failure patients with LBBB have mechanical asynchrony $[12,13]$.

Furthermore, asynchrony is common even in heart failure patients with narrow QRS complexes compared with healthy controls. A prospective study assessed left ventricular systolic and diastolic asynchrony in 67 patients with heart failure (LVEF $<50 \%$ ) with normal QRS width and 45 patients with CHF and wide QRS complexes $(>120$ ms). 88 healthy control patients were included. Systolic (diastolic) asynchrony occurs in 51\% (46\%) of the heart failure patients with narrow QRS complexes and in 73\% (69\%) in the patients with wide QRS complexes. Systolic asynchrony was defined as the max difference in time-topeak myocardial contraction of 12 myocardial segments. Diastolic asynchrony was defined as maximum difference of time-to-peak early diastolic relaxation. In summary, the authors state that asynchrony is common in patients with heart failure even without a wide QRS complex [14]. This is confirmed in a study with 158 heart failure patients (LVEF < 35\%), that were divided in three subgroups: Group 1 with no (QRS $<120 \mathrm{~ms}$ ), group 2 with mild (120-150 ms) and group 3 with severe LBBB (>150 ms). Interventricular asynchrony was defined by TDI as IVMD $>40 \mathrm{~ms}$ and the intraventricular delay as maximum preejection period of $>50 \mathrm{~ms}$ in one or more myocardial segments. Asynchrony was seen in all three subgroups, however, there was no correlation between interventricular and intraventricular asynchrony [15].

A recent study demonstrated that successful BVP can be achieved in patients with a normal QRS duration and asynchrony $[16,17]$.

These controversial data indicate the need for a more careful patient selection for BVP. Newer echocardiographic techniques, such as Tissue Doppler Imaging and Tissue Synchronization Imaging could potentially improve patient selection and guidance of implantation and programming of the devices for BVP. The risks of pacemaker implantation and expenses in non-responders to BVP could be avoided. Furthermore, the cost-effectiveness of BVP would be augmented.

\section{Definitions of asynchrony}

Regarding the nomenclature, the term "asynchrony" is used synonymously to "dyssynchrony" in this article. There is a variety of methods to determine asynchrony. In table 1, the different approaches to asynchrony are listed concisely. The QRS width (LBBB $>120,130,150 \mathrm{~ms}$ ) is the simplest method, but the sensitivity to predict benefit from BVP is rather low $[18,19]$. Magnetic resonance imaging can also detect areas of asynchrony but this technique can not be repeated for follow-up after device implantation.

Echocardiographic tools include 2D, Doppler and Tissue Doppler methods. Up to date, there is no consensus on the definition of echocardiographically measured myocardial asynchrony. The determination of asynchrony by M-mode echocardiography is limited to septal and inferior segments in parasternal long-axis and is not performed routinely in current studies [20,21]. Earlier echocardiographic approaches to asynchrony included the delayed long axis shortening that was found to suppress early diastolic transmitral flow and subsequently leading to decreased leftventricular function [22].

Tissue Doppler imaging (TDI) measures regional wall motion velocities. TDI can accurately quantify regional left ventricular function [23]. Pulsed wave TDI does not allow simultaneous comparison of regional timing in different segments within one cardiac cycle. Color-coded TDI 
reduces beat-to-beat variability and examination time. Color coded TDI has a very high time resolution of $10 \mathrm{~ms}$.

TDI technology includes tissue tracking and strain rate imaging. Tissue tracking allows the measurement and visualization of longitudinal motion in each myocardial segment during the different phases of the heart cycle.

Strain measures compression and distension of myocardial segments ("deformation imaging") and strain rate imaging expresses strain changes per time interval. Postsystolic movement diagnosed with velocity or tissue tracking can be differentiated into passive or active motion (=contraction, then defined as PSS). But in ischemic cardiomyopathy PSS was not an useful criterion for response to BVP because this phenomenon is not only a sign of asynchrony but also a marker for ischemia and/or viability of severe hypo/akinetic segments [24].

Tissue synchronization imaging (TSI) is a newer technique that utilizes color-coded time-to-peak tissue Doppler velocities and visualizes segments of dyssynchrony in real-time by superimposing these temporal motion data on 2D echo images. TSI analysis is possible in all myocardial regions except the apex. The color-coding is green (normal time-to-peak velocity: 20-150 ms), yellow (150$300 \mathrm{~ms}$ ) and red (300-500 ms) [25]. Online 3D echocardiography and automated border detection (ABD) might be future diagnostic tools to diagnose asynchrony but need evaluation in larger studies [26].

Myocardial asynchrony includes inter- and intraventricular asynchrony. Interventricular asynchrony can be assessed by comparing pw-Doppler signals in the right and left ventricular outflow tracts. A delay of $>60 \mathrm{~ms}$ is considered to demonstrate interventricular asynchrony. These measurements in the outflow tracts cannot be performed simultaneously and, therefore, there is a high inter-measurement variability and dependence on cardiac workload. In addition, interventricular asynchrony can measured as the difference of the electromechanical delays in the basal LV segments and the lateral RV segments [35].

Intra(left)ventricular asynchrony is considered to be the most important aspect of the electromechanical delay (EMD). It can be measured by a variety of methods. EMD is defined as the delay between the onset of the QRS complex on the surface ECG and the onset of the systolic TDI wave in corresponding myocardial segments. Recently, the systolic synchronicity index has been introduced [27]. It is defined as the standard deviation (SD) of the EMD in 12 LV segments (6 basal, 6 mid-segmental model).
Intraventricular asynchrony can also be demonstrated by tissue tracking with diastolic color-coded areas called DLC. This is the amount of post-systolic contraction after the closure of the aortic valve (i.e. post systolic shortening $=$ PSS) which was confirmed by strain and strain rate in this study [28].

Intra-left ventricular asynchrony is not only of diagnostic value for selecting patients for BVP, but has prognostic value as well. Bader et al. [3] examined inter- and intraventricular asynchrony as an independent predictor of heart failure worsening: 104 patients with chronic stable heart failure without previous myocardial infarction (LVEF < 45\%) were included, follow-up echocardiography was performed after one year. Study endpoint of heart failure worsening was hospitalization for cardiac decompensation. Intra-left ventricular asynchrony is an independent predictor of severe cardiac events. Only a weak correlation of intra/inter-ventricular EMD and QRS width could be demonstrated.

In figures $1,2,3,4,5,6,7,8,9$, the different approaches to assess asynchrony as well as echocardiographic examples of successful biventricular pacing are illustrated.

\section{Patient selection for BVP}

Only limited data are published concerning prospective echocardiography based patient selection for BVP. Bordachar et al. [29] performed a prospective study to identify TDI parameters that would predict the benefit of upgrading right ventricular pacing to BVP. 26 patients with normal LVEF and RVP and 16 patients with CHF and RVP were included. EMD was defined as the interval between the stimulation spike and the onset of the $S$ wave. An intra-ventricular EMD of $>50$ ms identifies patients with significant asynchrony. No correlation between asynchrony and QRS width was seen in the heart failure patients. ECG criteria would have misclassified $44 \%$ of the patients for mechanical ventricular asynchrony. This study has defined relevant asynchrony but did not assess the hemodynamic or electromechanical effects after upgrade to BVP nor effects on morbidity and mortality.

\section{Retrospective analysis after BVP}

Several studies were performed to retrospectively correlate markers of asynchrony to benefit from BVP.

Lafitte [30] has included 15 patients with idiopathic DCM and a QRS of more than 140 ms (NYHA III-IV, LVEF < $35 \%$, LVEDD > $60 \mathrm{~mm}$ ) for BVP. Measurement of EMD was performed at baseline and after one month. This study has found that BVP reduces EMD in the lateral left ventricular wall. 
Table I: Concise summary of the different approaches to echocardiographic measurement of asynchrony

\begin{tabular}{|c|c|c|c|c|c|c|}
\hline $\begin{array}{l}\text { Assessment of } \\
\text { asynchrony } \\
\text { with: }\end{array}$ & Ref. & Criteria & Segments & Limitations & $\begin{array}{l}\text { Analysis } \\
\text { time }\end{array}$ & $\begin{array}{l}\text { Prediction of } \\
\text { benefit }\end{array}$ \\
\hline \multicolumn{7}{|c|}{ I. Global ventricular asynchrony } \\
\hline ECG & 4,44 & QRS width $>120 \mathrm{~ms}$ & Global assessment & $\begin{array}{l}\text { LBBB after } \\
\text { myocardial } \\
\text { infarction }\end{array}$ & Short & $\begin{array}{l}\text { Low }(30 \% \text { non- } \\
\text { responder) }\end{array}$ \\
\hline M-mode & 21 & $\begin{array}{l}\text { Septal-to-posterior wall motion } \\
\text { delay }>130 \mathrm{~ms}\end{array}$ & $\begin{array}{l}\text { septal and } \\
\text { posterior }\end{array}$ & $\begin{array}{l}\text { scar tissue, only } \\
\text { septal or posterior }\end{array}$ & Short & low \\
\hline pw-TDI & 25 & $\begin{array}{l}\text { Cumulative asynchrony (EMD) } \\
>102 \mathrm{~ms}\end{array}$ & $\begin{array}{l}\text { Intra LV (5 basal } \\
\text { segments) and } \\
\text { interventricular } \\
\text { (vs. RV lateral } \\
\text { segment) }\end{array}$ & $\begin{array}{l}\text { Low spatial } \\
\text { resolution }\end{array}$ & Long & $\begin{array}{l}\text { Good prediction } \\
\text { of acute response } \\
\text { (AUC in ROC } \\
0,84 \text { ) }\end{array}$ \\
\hline
\end{tabular}

II. Interventricular asynchrony

\begin{tabular}{llllll}
\hline $\begin{array}{l}\text { pw-Doppler } \\
\text { echocardiograp }\end{array}$ & 47 & $\begin{array}{l}\text { Interventricular mechanical delay } \\
\text { (IVMD) }>40 \mathrm{~ms}\end{array}$ & $\begin{array}{l}\text { Aortic and } \\
\text { pulmonaryoutflow } \\
\text { hy }\end{array}$ & & tract
\end{tabular}

\section{Intraventricular asynchrony}

\begin{tabular}{|c|c|c|c|c|c|c|}
\hline \multirow[t]{4}{*}{ 2D-TDI } & 27 & $\begin{array}{l}\text { Ts-SD: intraventricular systolic } \\
\text { asynchrony index: }>33 \mathrm{~ms}\end{array}$ & 12 segments & $\begin{array}{l}\text { complex (post- } \\
\text { processing) }\end{array}$ & Long & $\begin{array}{l}\text { Acute response ( } 3 \\
\text { months) }\end{array}$ \\
\hline & 4,32 & $\begin{array}{l}\text { Difference in septal-lateral time- } \\
\text { to-peak TDI, cut-off }>60 \mathrm{~ms}\end{array}$ & 12 segments & Complex & Long & $\begin{array}{l}\text { EF increase after } \\
\text { BVP }\end{array}$ \\
\hline & 40 & $\begin{array}{l}\text { Mean regional myocardial } \\
\text { performance index: Difference } \\
\text { between regional Q-wave- } \\
\text { to.peak systolic displacement } \\
\text { times }\end{array}$ & $\begin{array}{l}12 \text { segments } \\
4 \text { segments }\end{array}$ & Complex & $\begin{array}{l}\text { Long, } \\
\text { offline }\end{array}$ & Acute response \\
\hline & 33 & Ts-SD: cut-off: $3 \mathrm{I}, 4 \mathrm{~ms}$ & 12 segments & Complex & Long & $\begin{array}{l}3 \text { months } \\
\text { response, reverse } \\
\text { remodeling }\end{array}$ \\
\hline $\begin{array}{l}\text { Strain and } \\
\text { strain rate }\end{array}$ & $15,34,33$ & $\begin{array}{l}\text { Myocardial deformation in } \\
\text { systole, presence of post-systolic } \\
\text { shortening }\end{array}$ & 12 segments & $\begin{array}{l}\text { Complex, time } \\
\text { consuming, in } \\
\text { dilated ventricles } \\
\text { low spatial } \\
\text { resolution) }\end{array}$ & Long & Controversial data \\
\hline Tissue Tracking & 28 & DLC in $>2$ basal segments & $\begin{array}{l}\text { I } 2 \text { basal segments } \\
\text { in apical four } \\
\text { chamber view. }\end{array}$ & $\begin{array}{l}\text { Requires correct } \\
\text { timing of LV } \\
\text { events }\end{array}$ & Short & Acute response \\
\hline TSI & 36 & $\begin{array}{l}\text { Color-coded time-to-peak tissue } \\
\text { Doppler velocities (cut-off }>65 \\
\text { ms in anteroseptum and } \\
\text { posterior wall in apical long axis } \\
\text { view) }\end{array}$ & $\begin{array}{l}16 \text { segments } \\
\text { except apex }\end{array}$ & Only velocity data & Short & $\begin{array}{l}\text { Acute response } \\
\text { (Sensitivity } 87 \% \\
\text { Specificity } 100 \% \text { ) }\end{array}$ \\
\hline 3-D-echo & 26 & No quantitative criteria defined & All segments & $\begin{array}{l}\text { Reduced spatial } \\
\text { resolution }\end{array}$ & $\begin{array}{l}\text { Time } \\
\text { consuming, } \\
\text { off-line } \\
\text { analysis }\end{array}$ & $\begin{array}{l}\text { No systematic } \\
\text { data }\end{array}$ \\
\hline $\begin{array}{l}\text { Automated } \\
\text { endocardial } \\
\text { border } \\
\text { detection } \\
\text { (ABD) }\end{array}$ & 26 & $\begin{array}{l}\text { Septal-lateral phase angle } \\
\text { difference }\end{array}$ & $\begin{array}{l}\text { I00 segments. } \\
\text { apical-four- } \\
\text { chamber view } \\
\text { (septal-lateral) }\end{array}$ & $\begin{array}{l}\text { High complexity, } \\
\text { single imaging } \\
\text { plane }\end{array}$ & $\begin{array}{l}\text { Long, only } \\
\text { off-line }\end{array}$ & Acute response \\
\hline ABD + Contrast & 46 & $\begin{array}{l}\text { Echo-contrast cardiac variability } \\
\text { imaging: displacement maps }\end{array}$ & $\begin{array}{l}\text { apical four } \\
\text { chamber }\end{array}$ & $\begin{array}{l}\text { High complexity, } \\
\text { single imaging } \\
\text { plane }\end{array}$ & Long & Acute response \\
\hline
\end{tabular}




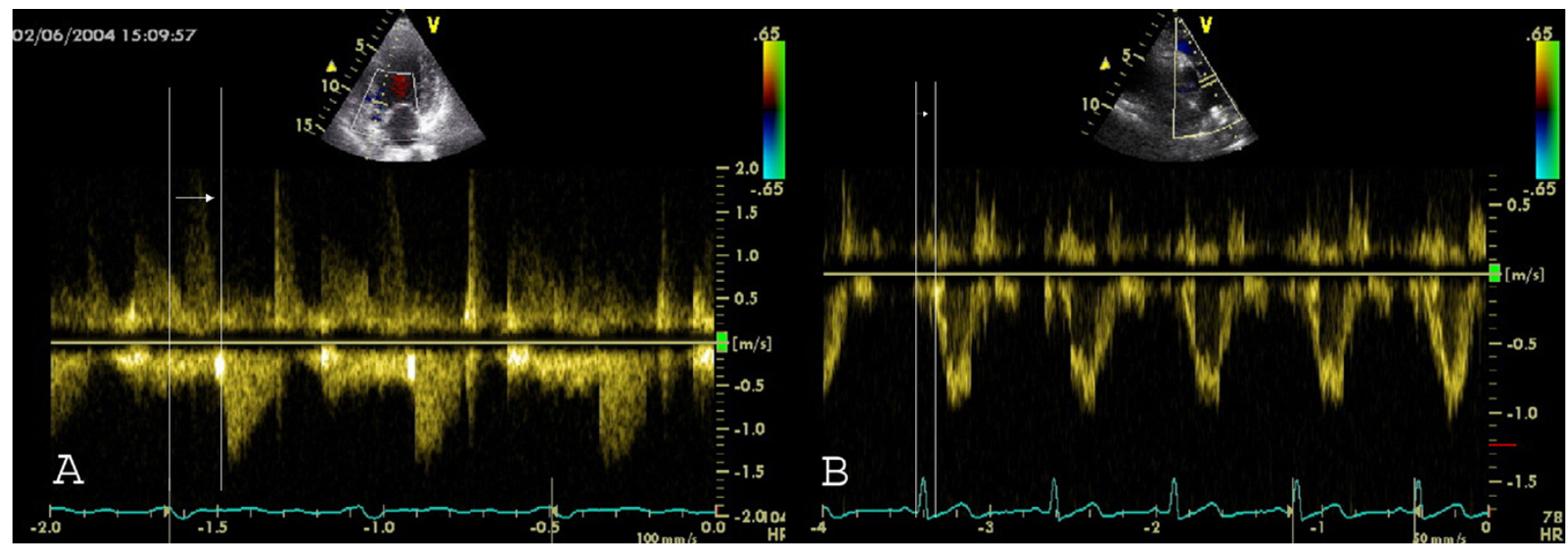

Figure I

Measurement of interventricular mechanical (IMD) delay by PW Doppler: A) PW Doppler in aortic outflow tract: Measurement from onset of QRS to the onset of PW curve in the aortic outflow tract. This time is also called the aortic preejection time and is a marker for intra(left)ventricular asynchrony. B) PW Doppler in pulmonary outflow tract: Measurement from onset of QRS to the onset of PW curve in the pulmonary outflow tract. The IMD is the difference between the time of a) and b).

In another study [25], 49 patients with heart failure (QRS $>130$ ms, LVEF < 35\%, NYHA II-IV) were included. Retrospectively, intra- and interventricular and the combined index of asynchrony (=the sum of left and right ventricular asynchrony) were assessed at baseline and after 6 months of BVP by pulsed wave TDI. The cut-off-values for LV-asynchrony was $60 \mathrm{~ms}$ (56 ms for RV-LV-asynchrony and $102 \mathrm{~ms}$ for the "sum-asynchrony"). By definition, patients with a relative increase in LVEF of more than 25\% were classified as responders to BVP. Receiver-operating characteristics (ROC) analysis showed that the degree of echocardiographic asynchrony is superior to QRS width in predicting hemodynamic and clinical improvement after BVP compared to QRS duration or conventional echo data. In $82 \%$ of the patients, the benefit of BVP could have been predicted echocardiographically.

The role of TDI and 3D echo on the long term (1 year) outcome after BVP was evaluated in 25 patients [19]. The extent of DLC in the basal segments at baseline predicted the long-term efficacy of BVP. The LV base DLC was reduced from $18,7 \%$ to $8.1 \%$ after BVP. In concordance with other studies, the QRS duration failed to predict BVP efficacy [28].

The myocardial segments with the best resynchronization after BVP were studied in 18 patients with an LVEF $<35 \%$ and a QRS width of $>120 \mathrm{~ms}$ (NYHA III-IV). Color tissue Doppler velocity imaging was performed from the apical four chamber view at baseline and one month of follow- up after BVP [31]. Peak velocities and regional time differences in basal and mid septal segments were compared to the corresponding lateral segments. At baseline, a regional asynchrony of $42 \mathrm{~ms}$ in the basal sites (only $14 \mathrm{~ms}$ in the mid left ventricular site) was measured. After one month of BVP, a reduction of asynchrony was seen in only the basal segments but not in the mid segments. In conclusion, it was suggested that hemodynamic improvement is mainly in basal sites.

Reverse remodeling and improved synchrony after 3 months of BVP was evaluated in 25 patients [32]. Asynchrony was assessed as time-to-peak regional sustained systolic contraction (=Ts). After three months, a homogenous left ventricular delay of Ts, improved interventricular synchrony and a reduced isovolumic contraction time and increased diastolic filling time were documented. These beneficial effects were reversible after withholding BVP. In a univariate analysis, systolic dyssynchrony was the only independent predictor of reverse remodeling after three months [33].

One recent study has compared the value of TDI and SRI and post-systolic shortening in the prediction of reverse remodeling after BVP: The previously introduced asynchrony index (=Ts-SD) based on Tissue Doppler velocity data has the highest predictive value of reverse remodeling after BVP. PSS has predictive power only in non-ischemic heart failure. In ischemic heart failure, PSS seems not to be a marker for reverse remodeling but rather reflects viabil- 


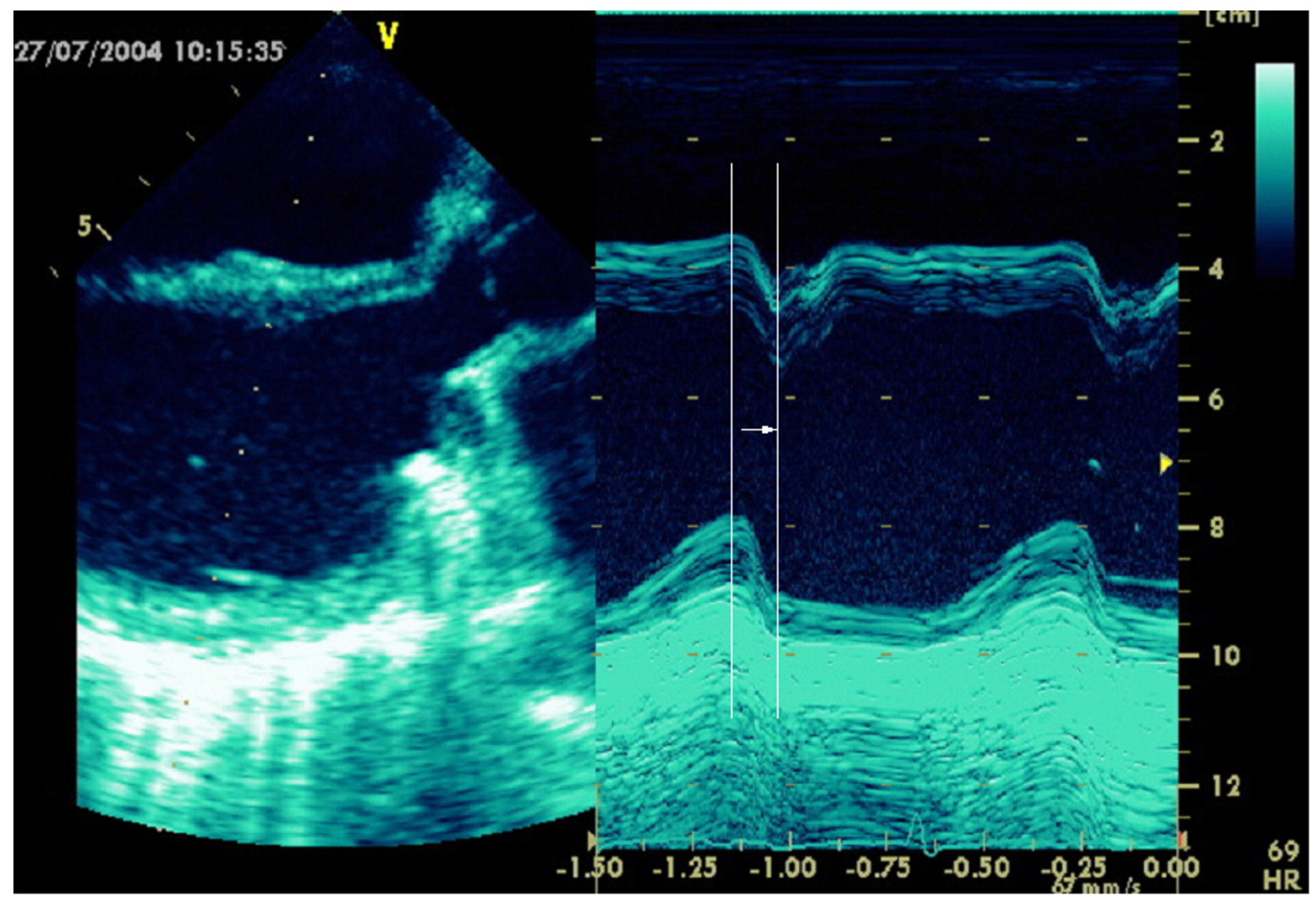

Figure 2

Assessment of asynchrony in parasternal long axis view by M-mode: Time difference between peak of septal and inferior myocardial contraction.

ity and is therefore not altered by BVP. SRI imaging techniques did not predict reverse remodeling after three months of BVP [33]. This is in contrast to previously published data [34].

Kanzaki has introduced the synchrony index, which is defined as the correlation coefficient of linear regression of velocity of septal and lateral mitral annular region. This index showed an increase after 6 months of BVP paralleled by increased LV contractility [35].

One study [36] has retrospectively evaluated the use of TSI to predict the acute response to BVP in 29 patients. The acute benefit to BVP was defined as a $>15 \%$ increase in echocardiographically measured stroke volume $48 \mathrm{~h}$ after device implantation. A difference of $>65 \mathrm{~ms}$ in time-topeak velocity in anteroseptal and posterior segments in the apical long axis view was associated with acute improvement after BVP. However, the ability of TSI to predict long-term improvement after BVP needs further evaluation.

\section{Guidance for implantation}

TDI could play a role in identifying patients during catheterization procedures that will profit from BVP. Catheterization studies have shown that the beneficial effects of BVP begin almost immediately $[37,38]$. But systematic evaluation with TDI-technique is currently ongoing.

Furthermore, TDI can assist in finding the optimal pacing site for the coronary sinus lead. In 31 patients, it was documented that LV-stimulation on the site of longest EMD had the best benefit of BVP. The regional asynchrony was assessed by pw-TDI and the pacing site was determined 


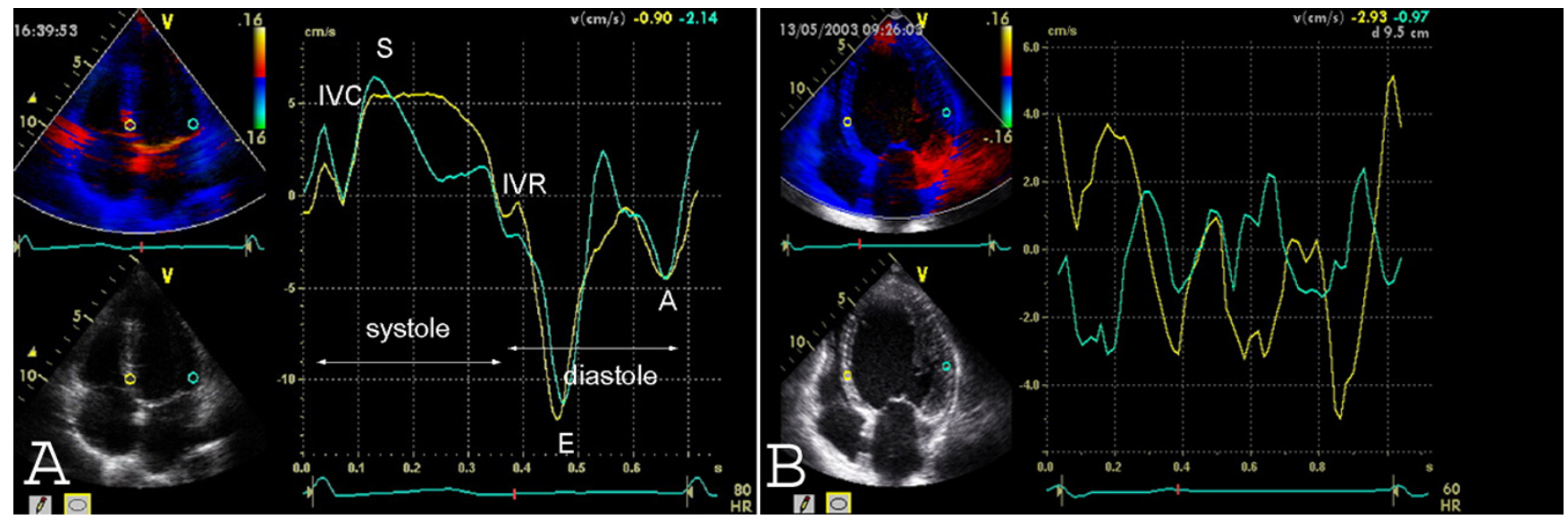

Figure 3

Tissue Doppler velocity data for the quantification of asynchrony from apical four chamber view. Sample volumes are in the basal lateral and basal septal segment. A) Normal control patient. There is a synchronous myocardial velocity in the septal (=yellow) and the lateral (=green curve) segment. IVC = isovolumetric contraction, IVR = isovolumetric relaxation, $\mathrm{S}=$ peak systolic velocity; $E$ = early diastolic filling, $A=$ late (atrial) diastolic filling. $B$ ) There is asynchronous myocardial velocity in the septal (=yellow) and the lateral (=green curve) segment.

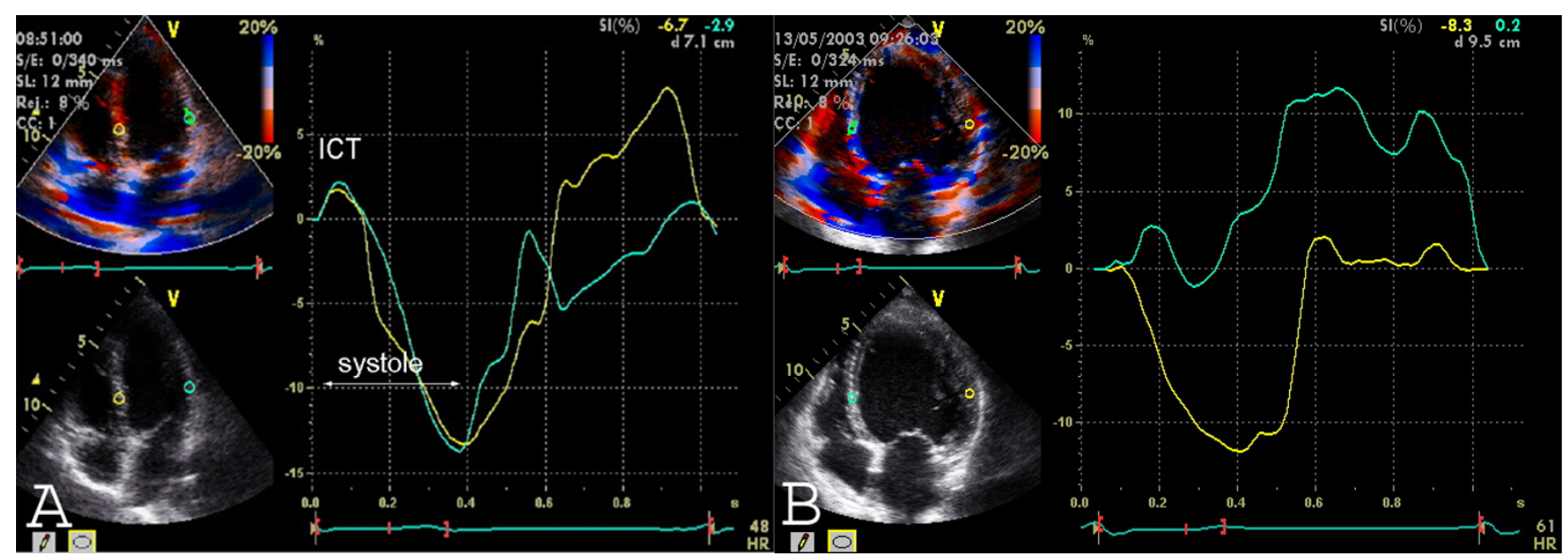

Figure 4

Assessment of asynchrony by strain from the apical four chamber view. The sample volumes are in the basal septal and the basal lateral segments. A) Normal strain curve in a control patient. ICT = isovolumetric contraction time. B) Strain curve with asynchronous myocardial velocity in the septal (=yellow) and the lateral (=green curve) segment.

fluoroscopically [39]. Lateral and postero-lateral LV lead positions were retrospectively found to improve left ventricular hemodynamics [40].

\section{Optimal programming of biventricular device after implantation \\ AV-time programming}

An AV time is considered to be optimal when the end of the A wave coincides with the complete closure of the mitral valve [41]. An optimal AV time setting of the pace- 


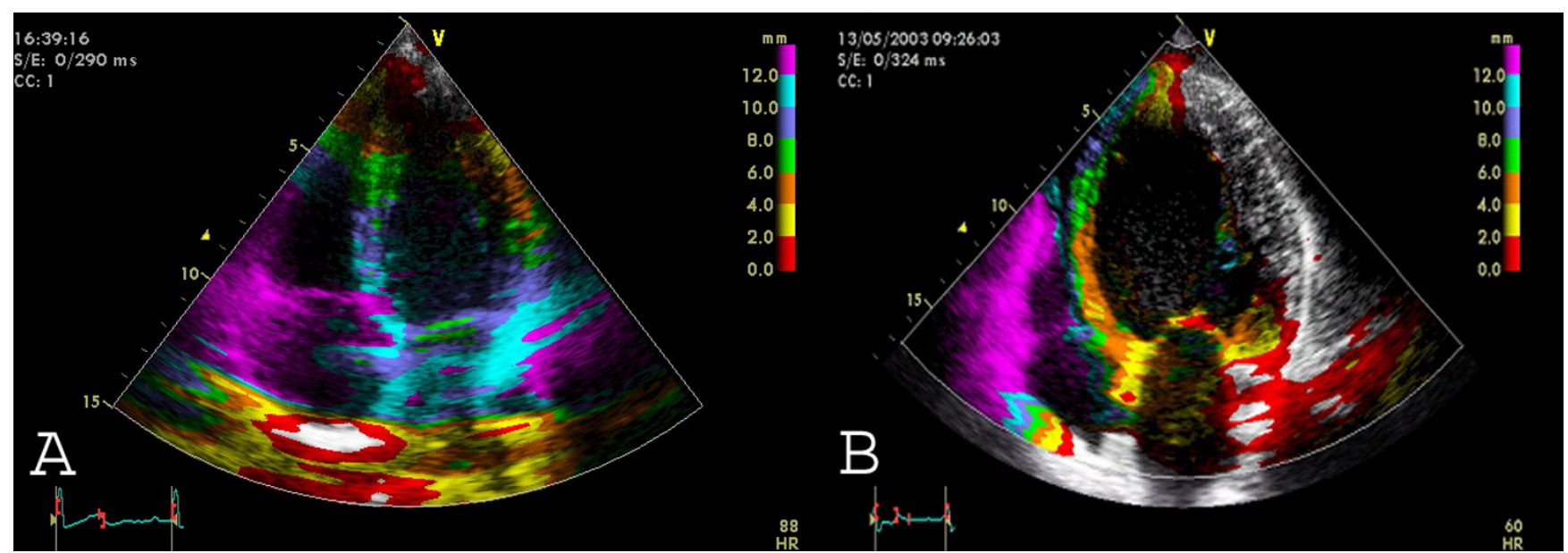

Figure 5

Tissue Tracking allows the visualization of longitudinal motion in each myocardial segment. Images are from the apical four chamber view. A) Normal control patient. There are normal colour-coded displacement values in the lateral and septal segments, with physiologically higher values in the more basal segments and lower values towards the apex. B) Tissue Tracking in a patient with dilated cardiomyopathy. There is a dilated left ventricle with "baseball shape" and reduced displacement values and no basal-apical gradient (max displacement $=8 \mathrm{~mm}$ ) in the septal segments and DLC in the lateral wall (no colour-coding) indicating asynchrony of the lateral wall.

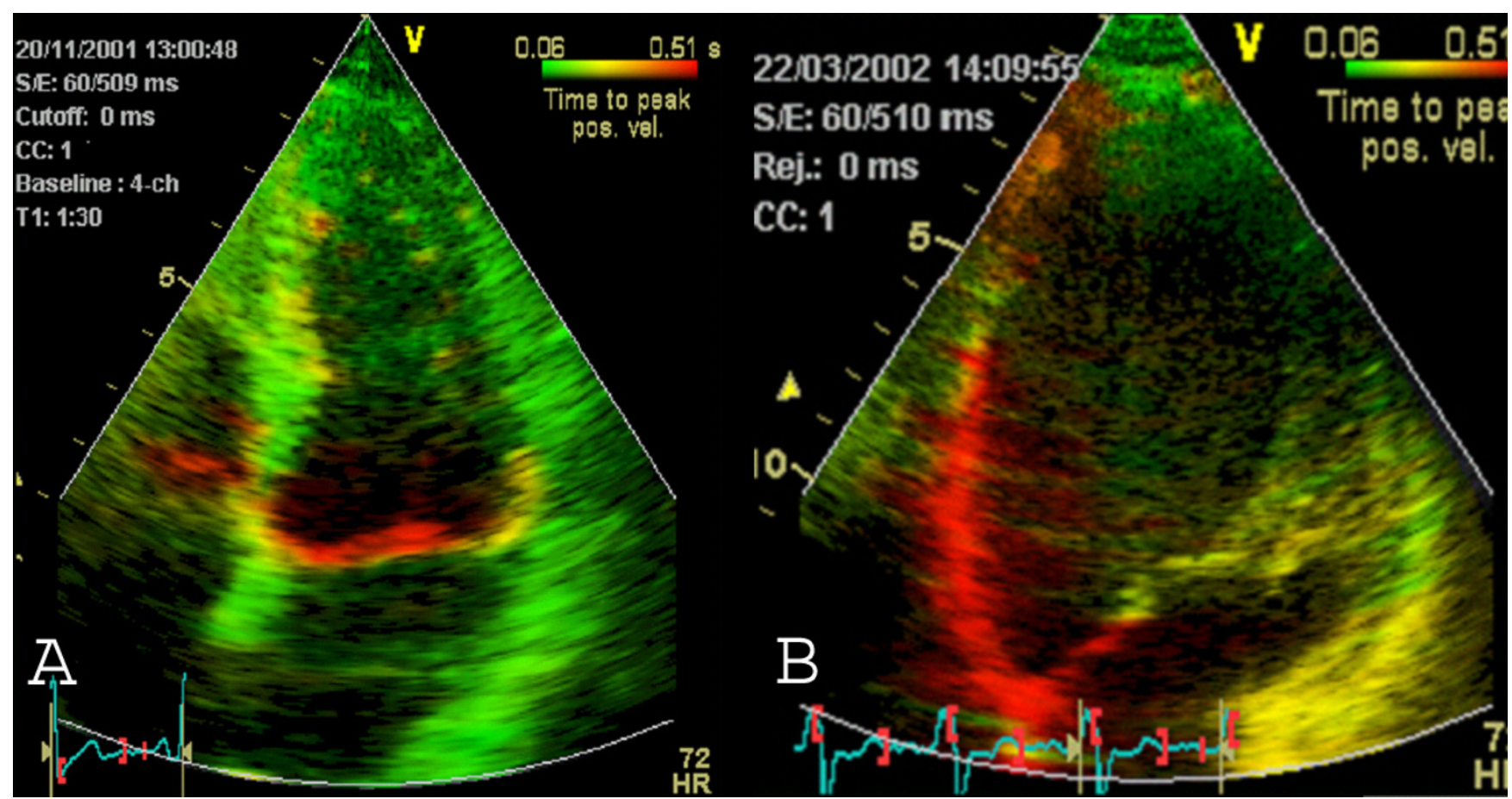

Figure 6

Tissue Synchronization Imaging displays colour-coded time-to-peak tissue Doppler velocities. The colour-coding is green (normal time-to-peak velocity: 20-150 ms), yellow (I50-300 ms) and red (300-500 ms) Apical four chamber view. A) TSI in a control patient (only green colour coding indicating synchronous contraction) B) TSI in a patient with LBBB: The basal and midseptal segments show a delayed time-to-peak velocity (red colour). 


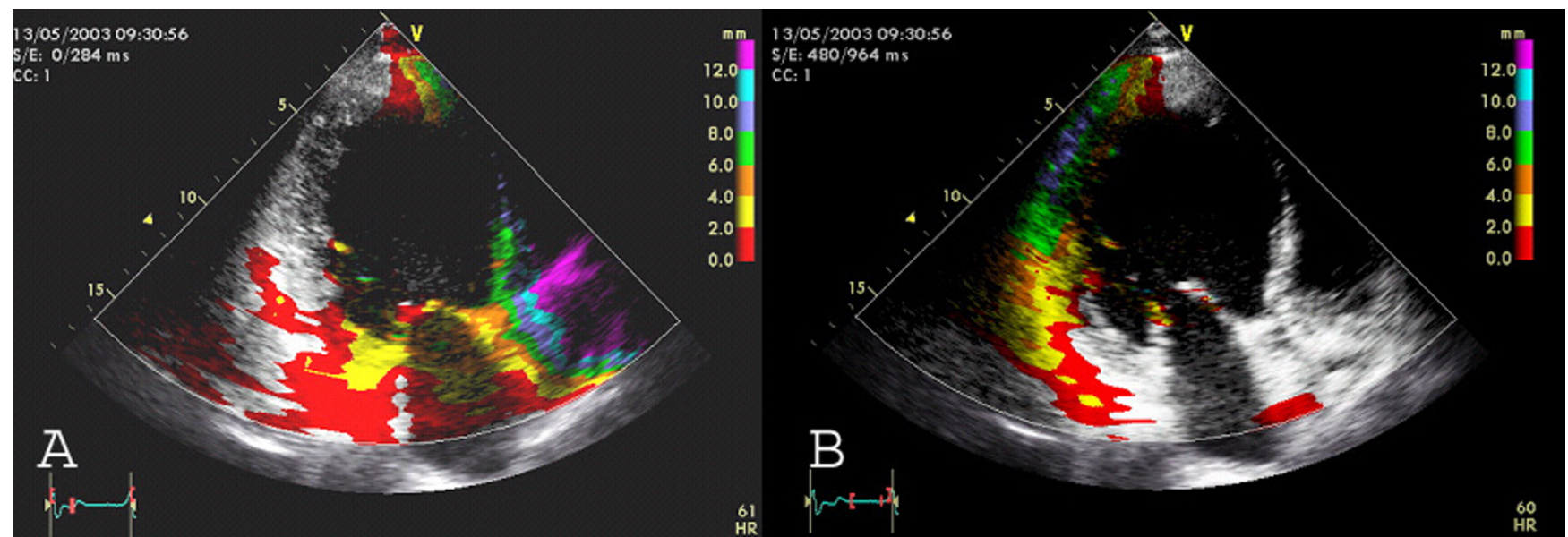

Figure 7

Delayed longitudinal contraction (=DLC) as a marker for asynchrony can be visualized by analysis of systolic and diastolic Tissue Tracking. Systolic tracking analyzes the systolic displacement i.e. tracking interval between the onset of QRS-complex and the end of the T-wave. Diastolic tracking can demonstrate DLC with colour coding (end of T until begin of R). Images from apical two chamber view A) Systolic Tracking: The inferior segments (=grey area) show DLC with no systolic motion B) Diastolic Tracking: The inferior segments (=colour coded area) show DLC with diastolic movement.

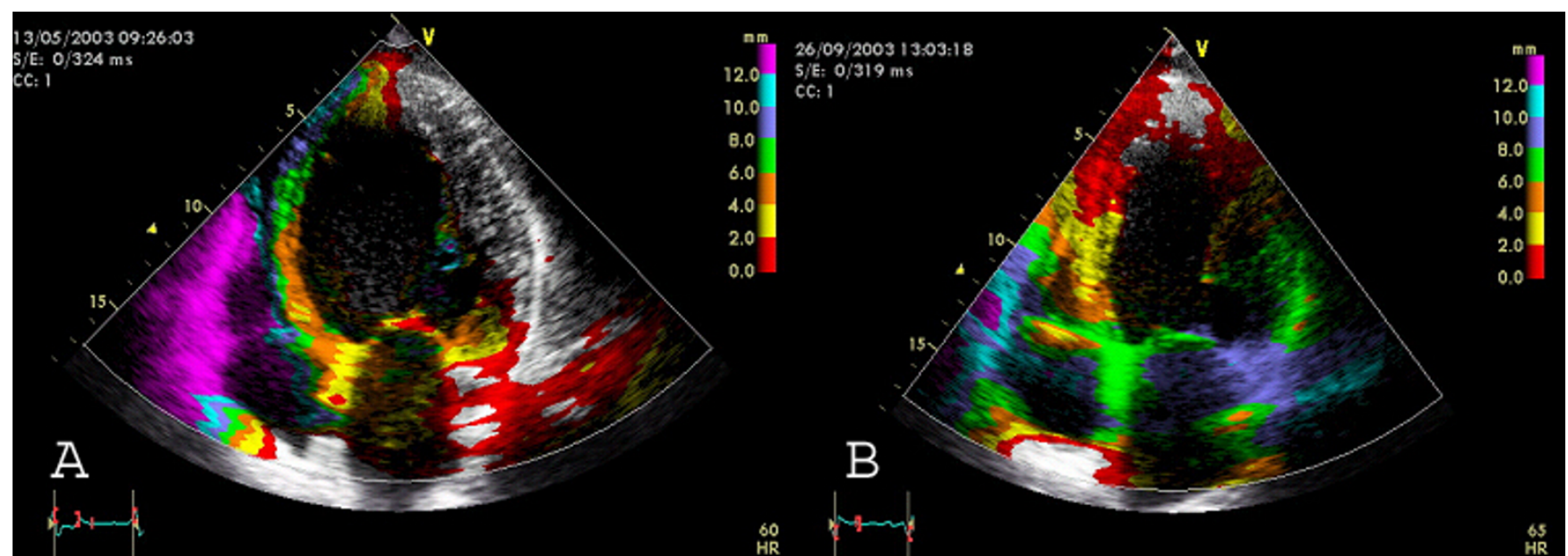

Figure 8

Demonstration of successful BVP by Tissue Tracking in apical four chamber view in a patient with dilated cardiomyopathy. Images from apical four chamber view. A) Before BVP, there is a dilated ventricle ("baseball shape") with reduced systolic displacement (max displacement $=8 \mathrm{~mm}$ ) in the septum and DLC in the lateral wall (no colour-coding) indicating asynchrony of the lateral wall. B) After three months of BVP, there is a reduction of left ventricular dilatation (reverse remodelling, "American football shape" of the left ventricle), increased tracking values and no DLC regions anymore.

maker can improve systolic function [42]. However, there is only limited published data assessing the optimal AV time in patients with BVP.

\section{Optimization of the interventricular delay}

The optimal delay between the right ventricular and the coronary sinus stimulation is yet unknown. One study compared simultaneous versus sequential BVP in 29 


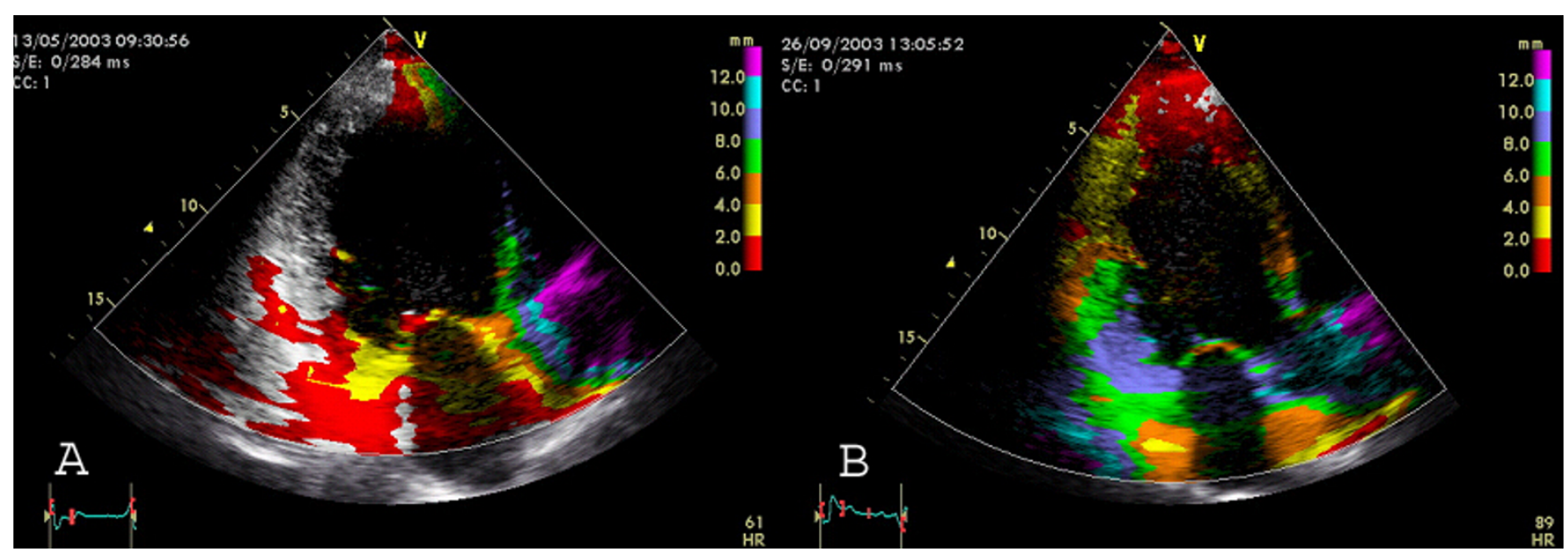

Figure 9

Successful BVP documented by Tissue Tracking in apical two chamber view. A) Before BVP, there is a dilated ventricle with reduced systolic displacement ( $\max$ displacement $=8 \mathrm{~mm}$ ) in the septum and DLC in the inferior wall (no colour-coding) $B$ ) After three months of BVP, there is a reduction of left ventricular dilatation (reverse remodelling), increased tracking values, a basal-apical gradient and no DLC regions anymore.

patients. The optimum interventricular delay was found by maximum reduction of DLC as measured by Tissue Doppler and Tissue Tracking. An optimum sequential BVP could significantly reduce the extent of DLC compared to simultaneous pacing [43].

\section{Patients with atrial fibrillation}

About one third of patients with heart failure have atrial fibrillation. The large trials, however, have only included patients in sinus rhythm. Only small studies with controversial results were performed in patients with atrial fibrillation and LBBB. Leclercq has performed one study in 59 NYHA III patients with chronic atrial fibrillation, a slow ventricular rate and the need for permanent pacing (VVIpaced QRS width of $>200 \mathrm{~ms}$ ). Due to a high drop out rate, the results did not show a significant increase in 6min-walk distance after BVP [44]. Larger trials are needed to evaluate BVP for patients with atrial fibrillation.

\section{Preliminary own results}

We have performed a double-blind cross-over study in our clinic to assess the use of new echocardiographic techniques in BVP. Patients $(\mathrm{n}=40)$ with a QRS $>140 \mathrm{~ms}$ and a LVEF $<35 \%$ received an InSyncICD 7272 (Medtronic, Minneapolis, Minnesota, USA). Preliminary results ( $\mathrm{n}=$ 8 ) after two years demonstrate a reduction of the septalposterior delay from $264( \pm 23) \mathrm{msec}$ to $234( \pm 34) \mathrm{msec}$ $(\mathrm{p}<0,05)$ and a stabilization of clinical (NYHA class improvement) and hemodynamic status (EF and LV volumes). The study is ongoing.

The following video loops underline the utility of TSI and Tissue Tracking to document improvement of synchronicity after BVP. In additional file 1 shows asynchrony before BVP implantation in apical four chamber view by TSI. In additional file 2 the effect of BVP is shown. in additional file 4 shows the acute changes of BVP as documented in this video loop by Tissue Tracking from apical four chamber view compared to baseline (additional file 3). The long-term effect of BVP after six months is illustrated in additional file 5 (baseline) and additional file 6 (after 6 months).

\section{Conclusion and future perspective}

Many controlled and uncontrolled studies have demonstrated that new echocardiographic tools to determine myocardial asynchrony in heart failure patients will help to select patients for BVP help guidance of implantation and optimize device programming. To date, all studies employing tissue Doppler date were performed retrospectively. No prospective studies that have selected patients for BVP according to echocardiographic evaluation of asynchrony were performed yet. The ongoing CARE-HF study incorporates echocardiographic criteria of asynchrony in a subset of patients with a QRS of 120-150 ms [45]; results are not expected until 2005. The criteria of asynchrony in this study are (1) aortic pre-ejection delay 
$>140 \mathrm{~ms}$, (2) the mechanical interventricular (pw aortic valve vs. pulmonary valve) delay $>40 \mathrm{~ms}$ and (3) the demonstration of left ventricular post-systolic contraction by M-mode and/or Tissue Doppler.

Unresolved issues include different opinions regarding the various elements of asynchrony and their contribution to the pathophysiology and progression of heart failure. There is a lack of consensus about the best asynchrony marker for patient selection. There is evidence that ischemic and dilated cardiomyopathy might have different selection parameters for BVP. The practical consequences for patient selection and/or implantation site of the lead are currently under investigation. There are only limited echocardiographic data regarding the programming of the optimal interventricular $(\mathrm{V}-\mathrm{V})$ delay. There are no data concerning the long-term effect (i.e. years) of BVP on hemodynamics, amelioration of mitral regurgitation, reverse remodeling and mortality. Another area of uncertainty is the selection of patients for BVP without electrical (QRS < 120 ms) but with mechanical asynchrony.

\section{Abbreviations \\ BVP Biventricular Pacing}

DCM Dilated Cardiomyopathy

DLC Delayed longitudinal Contraction

EMD Electromechanical Delay

IVMD Interventricular Mechanical Delay

LBBB Left Bundle Branch Block

PSS Post-Systolic Shortening

SRI Strain Rate Imaging

TDI Tissue Doppler Imaging

Ts Time-to-peak myocardial contraction

TSI Tissue Synchronization Imaging

Ts-SD Standard deviation of time-to-peak myocardial contraction

\section{Authors contributions}

$\mathrm{F}$ Knebel and AC Borges have performed the literature review and have prepared the manuscript. RK Reibis, have performed echocardiographic examinations for this article. HJ Bondke and J Witte and G Baumann have selected patients for BVP. HJ Bondke and J Witte have implanted the biventricular pacing devices. All authors have read and approved the final version of the manuscript.

\section{Additional material}

\section{Additional File 1}

TSI in a patient with LBBB before BVP: The lateral segments show a delayed time-to-peak velocity (red colour). Apical four chamber view. Click here for file

[http://www.biomedcentral.com/content/supplementary/1476-

7120-2-17-S1.zip]

\section{Additional File 2}

TSI post-implantation: There is only green colour coding indicating synchronous contraction of all segments from apical four chamber view. Click here for file

[http://www.biomedcentral.com/content/supplementary/14767120-2-17-S2.zip]

\section{Additional File 3}

Tissue Tracking without BVP: There are reduced displacement values and no basal-apical gradient in the septal segments and DLC in the lateral wall (no colour-coding) indicating asynchrony of the lateral wall. Apical four chamber view.

Click here for file

[http://www.biomedcentral.com/content/supplementary/14767120-2-17-S3.zip]

\section{Additional File 4}

Acute effect with BVP "on" (Tissue Tracking): There are increased displacement values, a basal-apical gradient. Apical four chamber view. Click here for file

[http://www.biomedcentral.com/content/supplementary/14767120-2-17-S4.zip]

\section{Additional File 5}

Tissue Tracking before BVP : There are reduced displacement values and no basal-apical gradient in the septal segments and DLC in the lateral wall. Apical four chamber view.

Click here for file

[http://www.biomedcentral.com/content/supplementary/14767120-2-17-S5.zip]

\section{Additional File 6}

Long-term effect after 6 months of BVP: Reduction of left ventricular dilatation, increased displacement values, a basal-apical gradient. Apical four chamber view.

Click here for file

[http://www.biomedcentral.com/content/supplementary/1476-

7120-2-17-S6.zip]

\section{References}

I. Venkateshwar K, Gottipaty VK, Krelis SP, Lu F, Spencer EP, Shusterman V, Weiss R, Brode S, White A, Anderson KP, White BG, Feldman $A M$, For the VEST investigators: The resting electrocardiogram provides a sensitive and inexpensive marker of prognosis in patients with chronic congestive heart failure. J Am Coll Card 1999, 33: 145 (Abstract).

2. Bode-Schnurbus L, Bocker D, Block M, Gradaus R, Heinecke A Breithardt G, Borggrefe M: QRS duration: a simple marker for 
predicting cardiac mortality in ICD patients with heart failure. Heart 2003, 89(10): I I57-I I62.

3. Bader H, Garrigue S, Lafitte S, Reuter S, Jais P, Haissaguerre M, Bonnet J, Clementy J, Roudaut R: Intra-left ventricular electromechanical asynchrony. A new independentpredictor of severe cardiac events in heart failure patients. J Am Coll Cardiol 2004, 43(2):248-256.

4. Bax JJ, Ansalone G, Breithardt OA, Derumeaux G, Leclercq C, Schalij MJ, Sogaard P, St John Sutton M, Nihoyannopoulos P: Echocardiographic evaluation of cardiac resynchronization therapy: ready for routine clinical use? A critical appraisal. J Am Coll Cardiol 2004, 44(I): I-9.

5. Bristow MR, Saxon LA, Boehmer J, Krueger S, Kass DA, De Marco T, Carson P, DiCarlo L, DeMets D, White BG, DeVries DW, Feldman AM, Comparison of Medical Therapy, Pacing, and Defibrillation in Heart Failure (COMPANION) Investigators: Cardiac Resynchronization Therapy with or without an Implantable Defibrillator in Advanced Chronic Heart Failure. N Eng J Med 2004, 350:2140-2150.

6. Linde C, Leclerca C, Rex S, Garrigue S, Lavergne T, Cazeau S, McKenna W, Fitzgerald M, Deharo JC, Alonso C, Walker S, Braunschweig F, Bailleul C, Daubert JC: Long-term benefits of biventricular pacing in congestive heart failure: results from the MUltisite STimulation in cardiomyopathy (MUSTIC) study. J Am Coll Cardiol 2002, 40: III-II8.

7. Abraham WT, Fisher WG, Smith AL, Delurgio DB, Leon AR, Loh E, Kocovic DZ, Packer M, Clavell AL, Hayes DL, Ellestad M, Trupp RJ, Underwood J, Pickering F, Truex C, cAtee P, Messenger J, MIRACLE Study Group: Multicenter InSync Randomized Clinical evaluation. Cardiac resynchronization in chronic heart failure. $N$ Engl J Med 2002, 346: I845- I853.

8. Cazeau S, Leclercq C, Lavergne T, Walker S, Varma C, Linde C, Garrigue S, Kappenberger L, Haywood GA, Santini M, Bailleul C, Daubert JC, Multisite Stimulation in Cardiomyopathies (MUSTIC) Study Investigators: Effects of multisite biventricualr pacing in patients with heart failure and intraventricular conduction delay. $N$ Engl J Med 200I, 344:873-880.

9. Saxon LA, De Marco T, Schafer J, Chatterjee K, Kumar UN, Foster E: VIGOR Congestive Heart Failure Investigators. Effects of long-term biventricular stimulation for resynchronization on echocardiographic measures of remodeling. Circulation 2002, 105:1304-1310.

10. Sundell J, Engblom E, Koistinen J, Ylitalo A, Naum A, Stolen KQ, Kalliokoski R, Nekolla SG, Airaksinen KE, Bax JJ, Knuuti J: The effects of cardiac resynchronization therapy on left ventricular function, myocardial energetics, and metabolic reserve in patients with dilated cardiomyopathy and heart failure. J Am Coll Cardiol 2004, 43(6): 1027-1033.

1I. Gregoratos G, Abrams J, Epstein AE, Freedman RA, Hayes DL, Hlatky MA, Kerber RE, Naccarelli GV, Schoenfeld MH, Silka MJ, Winters SL, Gibbons RI, Antman EM, Alpert JS, Hiratzka LF, Faxon DP, Jacobs AK, Fuster V, Smith SC Jr, American College of Cardiology/American Heart Association Task Force on Practice Guidelines American College of Cardiology/American Heart Association/North American Society for Pacing and Electrophysiology Committee: ACC/AHA/ NASPE 2002 guideline update for implantation of cardiac pacemakers and antiarrhythmia devices: summary article. A report of the American College of Cardiology/American Heart Association Task Force on Practice Guidelines (ACC/ AHA/NASPE Committee to Update the 1998 Pacemaker Guidelines). J Cardiovasc Electrophysiol 2002, I I : I |83- I | 99.

12. Ansalone G, Giannantoni P, Ricci R, Trambaiolo P, Fedele F, Santini M: Biventricular pacing in heart failure: back to basics in the pathophysiology of left bundle branch block to reduce the number of nonresponders. Am J Cardiol 2003, 9 I:55F-6 IF.

13. Faber L, Lamp B, Vogt J, Horstkotte D: Tissue Doppler imaging in patients with congestive heart failure and conduction disorders. Eur Heart J Supplement D 2004:DI0-DI5.

14. Yu CM, Lin H, Zhang Q, Sanderson JE: High prevalence of left ventricular systolic and diastolic asynchrony in patients with congestive heart failure and normal QRS duration. Heart 2003, 89:54-60.

15. Ghio S, Constantin C, Klersy C, Serio A, Fontana A, Campana C, Tavazzi $L$ : Interventricular and intraventricular dyssynchrony are common in heart failure patients, regardless of QRS duration. Eur Heart J 2004, 25(7):57I-578.
16. Vinereanu D, Bleasdale R, Turner M, Frenneaux MP, Fraser AG: Comparison of left ventricular-biventricular pacing on ventricular synchrony, mitral regurgitation, and global left ventricular function in patients with severe chronic heart failure. Am J Cardiol 2004, 94(4):519-52I.

17. Turner MS, Bleasdale RA, Vinereanu D, Mumford CE, Paul V, Fraser AG, Frenneaux MP: Electrical and mechanical components of dyssynchrony in heart failure patients with normal QRS duration and left bundle-branch block: impact of left and biventricular pacing. Circulation 2004, 109(21):2544-2249.

18. Ansalone G, Giannantoni P, Ricci R, Trambaiolo P, Laurenti A, Fedele F, Santini M: Doppler Myocardial Imaging in Patients with heart failure receiving biventricular pacing treatment. $\mathrm{Am}$ Heart J 200I, I 42:88I-896.

19. Auricchio A, Yu CM: Beyond the measurement of QRS complex toward mechanical dyssynchrony: cardiac resynchronisation therapy in heart failure patients with a normal QRS duration. Heart 2004, 90:479-48I.

20. Moynihan PF, Parisi AF, Feldman CL: Quantitative detection of regional left ventricular contraction abnormalities by two dimensional echocardiography. I. Analysis of methods. Circulation 198I, 63:752-760.

21. Pitzalis MV, lacoviello M, Romito R, Massari F, Rizzon B, Luzzi G, Guida P, Andriani A, Mastropasqua F, Rizzon P: Cardiac resynchronization therapy tailored by echocardiographic evaluation of ventricular asynchrony. I Am Coll Cardiol 2002, 40:16I5-1622.

22. Henein MY, Gibson DG: Suppression of left ventricular early diastolic filling by long axis asynchrony. Br Heart J 1995, 73(2): $15|-| 57$.

23. Borges AC, Kivelitz D, Walde T, Reibis RK, Grohmann A, Panda A, Wernecke KD, Rutsch W, Hamm B, Baumann G: Apical tissue tracking echocardiography for characterization of regional left ventricular function: comparison with magnetic resonance imaging in patients after myocardial infarction. $J \mathrm{Am}$ Soc Echocardiogr 2003, 3:254-262.

24. Mele D, Pasanisi G, Heimdal A, Cittanti C, Guardigli G, Levine RA, Sutherland G, Ferrari R: Improved recognition of dysfunctioning myocardial segments by longitudinal strain rate versus velocity in patients with myocardial infarction. J Am Soc Echocardiogr 2004:313-32I.

25. Penicka M, Bartunek J, De Bruyne B, Vanderheyden M, Goethals M, De Zutter M, Brugada P, Geelen P: Improvement of left ventricular function after cardiac resynchronization therapy is predicted by tissue Doppler imaging echocardiography. Circulation 2004, 109:978-983.

26. Breithardt OA, Stellbrink C, Kramer AP, Sinha AM, Franke A, Salo R, Schiffgens B, Huvelle E, Auricchio A, PATH-CHF Study Group: Pacing Therapies for Congestive Heart Failure. Echocardiographic quantification of left ventricular asynchrony predicts an acute hemodynamic benefit of cardiac resynchronization therapy. J Am Coll Cardiol 2002, 40:536-545.

27. Yu CM, Chau E, Sanderson JE, Fan K, Tang MO, Fung WH, Lin H, Kong SL, Lam YM, Hill MR, Lau CP: Tissue Doppler echocardiographic evidence of reverse remodeling and improved synchronicity by simultaneously delaying regional contraction after biventricular pacing therapy in heart failure. Circulation 2002, 105:438-445.

28. Sogaard P, Egeblad H, Kim WY, Jensen HK, Pedersen AK, Kristensen $\mathrm{BO}$, Mortensen PT: Tissue Doppler imaging predicts improved systolic performance and reversed left ventricular remodeling during long-term cardiac resynchronization therapy. J Am Coll Cardiol 2002, 40:723-730.

29. Bordachar P, Garrigue S, Lafitte S, Reuter S, Jais P, Haissaguerre M, Clementy J: Interventricular and intra-left ventricular electromechanical delays in right ventricular paced patients with heart failure: implications for upgrading to biventricular stimulation. Heart 2003, 89: | 40 I-I405.

30. Lafitte S, Garrigue S, Perron JM, Bordachar P, Reuter S, Jais P, Haissaguerre M, Clementy J, Roudaut R: Improvement of left ventricular wall synchronization with multisite ventricular pacing in heart failure: a prospective study using Doppler tissue imaging. Eur J Heart Fail 2004, 6:203-212.

31. Schuster P, Faerestrand S, Ohm OJ: Colour tissue velocity imaging can show resynchronisation of longitudinal left ventricular contraction pattern by biventricular pacing in patients with severe heart failure. Heart 2003, 89:859-864. 
32. Yu CM, Fung WH, Lin H, Zhang Q, Sanderson JE, Lau CP: Predictors of left ventricular reverse remodeling after cardiac resynchronization therapy for heart failure secondary to idiopathic dilated or ischemic cardiomyopathy. Am J Cardiol 2002, 91:684-688.

33. Yu CM, Fung JW, Zhang Q, Chan CK, Chan YS, Lin H, Kum LC, Kong SL, Zhang Y, Sanderson JE: Tissue Doppler imaging is superior to strain rate imaging and postsystolic shortening on the prediction of reverse remodeling in both ischemic and nonischemic heart failure after cardiac resynchronization therapy. Circulation 2004, I I O(I):66-73.

34. Breithardt OA, Herbots L, D'Hooge J, Claus P, Bijnens B, Stellbrink C, Franke A, Sutherland GR: Strain Rate Imaging in CRT Canditates. Eur Heart J Supplement D 2004:D 16-D24.

35. Kanzaki H, Jacques D, Sade LE, Severyn DA, Schwartzman D, Gorcsan J 3rd: Regional correlation by color-coded tissue Doppler to quantify improvements in mechanical left ventricular synchrony after biventricular pacing therapy. Am J Cardiol 2003, 92:752-755.

36. Gorcsan J, Kanzaki H, Bazaz R, Dohi K, Schwartzman D: Usefulness of Echocardiografic Tissue Synchronization Imaging to Predict Acute Response to Cardiac Resynchronization Therapy. Am J Cardiol 2004, 93: I I78-I I8I.

37. Nelson GS, Berger RD, Fetics BJ, Talbot M, Spinelli JC, Hare JM, Kass $\mathrm{DA}$ : Left ventricular or biventricular pacing improves cardiac function at diminished energy cost in patients with dilated cardiomyopathy and left bundle-branch block. Circulation 2000, 1 02(25):3053-3059. Erratum in: Circulation 2001, 103: 476

38. Kass DA, Chen CH, Curry C, Talbot M, Berger R, Fetics B, Nevo E: Improved left ventricular mechanics from acute VDD pacing in patients with dilated cardiomyopathy and ventricular conduction delay. Circulation 1999, 99:1567-1573.

39. Ansalone G, Giannantoni P, Ricci R, Trambaiolo P, Fedele F, Santini M: Doppler myocardial imaging to evaluate the effectiveness of pacing sites in patients receiving biventricular pacing. J Am Coll Cardiol 2002, 39:489-499.

40. Sun JP, Chinchoy E, Donal E, Popovic ZB, Perlic G, Asher CR, Greenberg NL, Grimm RA, Wilkoff BL, Thomas JD: Evaluation of ventricular synchrony using novel Doppler echocardiographic indices in patients with heart failure receiving cardiac resynchronization therapy. J Am Soc Echocardiogr 2004:845-850.

41. Ishigawa T, Sumita S, Kimura K, Kikuchi M, Kosuge M, Kuji N, Endo T, Sugano T, Sigemasa T, Kobayashi I, Tochikubo O, Usui T: Prediction of optimal atrioventricular delay in patients with implanted DDD pacemakers. Pacing Clin Electrophysiol 1999, 22:|365-|37|.

42. Kindermann M, Frohlig G, Doerr T, Schieffer H: Optimizing the AV delay in DDD pacemaker patients with high degree AV block: mitral valve Doppler versus impedance cardiography. Pacing Clin Electrophysiol 1997, 20:2453-2462.

43. Sogaard P, Egeblad H, Pedersen AK, Kim WY, Kristensen BO, Hansen PS, Mortensen PT: Sequential versus simultaneous biventricular resynchronization for severe heart failure: evaluation by tissue Doppler imaging. Circulation 2002, 106:2078-2084.

44. Leclercq C, Walker S, Linde C, Clementy J, Marshall AJ, Ritter P, Djiane P, Mabo P, Levy T, Gadler F, Bailleul C, Daubert JC: Comparative effects of permanent biventricular and right-univentricular pacing in heart failure patients with chronic atrial fibrillation. Eur Heart J 2002, 22: I 780- I 787.

45. Cleland JG, Daubert JC, Erdmann E, Freemantle N, Gras D, Kappenberger L, Klein W, Tavazzi L, CARE-HF study Steering Committee and Investigators: The CARE-HF study (CArdiac REsynchronisation in Heart Failure study): rationale, design and endpoints. Eur J Heart Fail 200I, 4:48I-489.

46. Kawaguchi M, Murabayashi T, Fetics BJ, Nelson GS, Samejima H, Nevo E, Kass DA: Quantitation of basal dyssynchrony and acute resynchronization from left or biventricular pacing by novel echo-contrast variability imaging. J Am Coll Cardiol 2002, 39(I 2):2052-2058.

47. Rouleau F, Merheb M, Geffroy S, Berthelot J, Chaleil D, Dupuis JM, Victor J, Geslin P: Echocardiographic assessment of the interventricular delay of activation and correlation to the QRS width in dilated cardiomyopathy. Pacing Clin Electrophysiol 200I, 10:1500-1506.

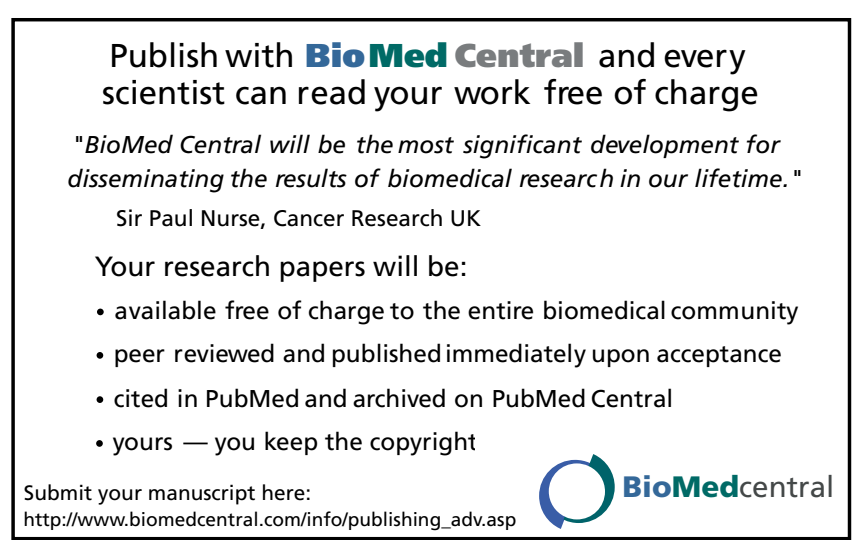

